\title{
Circulating concentrations of soluble L-selectin (CD62L) in patients with primary Sjögren's syndrome
}

\begin{abstract}
Mario García-Carrasco, Pilar Pizcueta, Ricard Cervera, Manuel Ramos-Casals, Antoni Sisó, Gloria de la Red, Miguel Ingelmo, Josep Font, Pablo Engel
\end{abstract}

Systemic Autoimmune

Diseases Unit,

Department of

Medicine, Institut

d'Investigacions

Biomèdiques August

Pi i Sunyer, Hospital

Clínic, School of

Medicine, University

of Barcelona,

Barcelona, Catalonia,

Spain

M García-Carrasco

R Cervera

M Ramos-Casals

A Sisó

G de la Red

J Font

$M$ Ingelmo

Hepatic

Haemodynamic

Laboratory, Liver Unit

P Pizcueta

Immunology Unit,

Department of

Cellular Biology and

Pathology

P Engel

Department of

Rheumatology,

Denernévita

Universidad

Autonoma de Puebla,

Puebla, Maxico

M García-Carrasco

Correspondence to:

Dr Font, Unitat de Malalties Autoimmunes Sistèmiques,

Hospital Clínic, C/Villarroel,

170, 08036-Barcelona,

Catalonia, Spain

Accepted for publication 22 November 1999 \section{SS.}

Objective-Serum concentrations of soluble (s) L-selectin (CD62L) were measured in patients with primary Sjögren's syndrome (SS) to relate these concentrations to clinical and immunological features of

Methods-The study included 40 consecutive patients ( 38 women and two men) with a mean age of 61 years (range 24-78) who fulfilled four or more of the preliminary diagnostic criteria for SS proposed by the European Community Study Group in 1993, and 33 healthy blood donors from the hospital blood bank. A sandwich enzyme linked immunosorbent assay (ELISA) was used to detect the soluble form of human sL-selectin (CD62L).

Results-The mean (SEM) values of sLselectin (CD62L) were 861 (66) $\mu \mathrm{g} / \mathrm{ml}$ for patients with SS and $986(180) \mu \mathrm{g} / \mathrm{ml}$ for healthy blood donors, but there was no significant difference. In patients with primary SS, serum sL-selectin (CD62L) concentrations were significantly higher in patients with Raynaud's phenomenon (1275 (112) $\mu \mathrm{g} / \mathrm{ml}$ versus 789 (69) $\mu \mathrm{g} / \mathrm{ml}$, $\mathbf{p}=0.007)$, autoimmune thyroiditis $(1162$ (113) $\mu \mathrm{g} / \mathrm{ml}$ versus 787 (69) $\mu \mathrm{g} / \mathrm{ml}, \mathrm{p}=0.02$ ) and rheumatoid factor (993 (95) $\mu \mathrm{g} / \mathrm{ml}$ versus $684(70) \mu \mathrm{g} / \mathrm{ml}, \mathrm{p}=0.01)$ when compared with patients without these feaConclusion-The presence of Raynaud's phenomenon, autoimmune thyroiditis and rheumatoid factor is associated with higher concentrations of circulating sLselectin (CD62L) in the sera of patients with primary SS.

(Ann Rheum Dis 2000;59:297-299)

Sjögren's syndrome (SS) is an autoimmune disease that mainly affects exocrine glands and that usually presents as a persistent dryness of the mouth and the eyes resulting from functional impairment of the salivary and lacrimal glands. ${ }^{1}$ The spectrum of the disease extends from an organ specific autoimmune disease (autoimmune exocrinopathy) ${ }^{2}$ to a systemic process (musculoskeletal, pulmonary, gastric, haematological, vascular, dermatological, renal and nervous system involvement). ${ }^{3}$ In the absence of an associated systemic autoimmune disease, patients with this condition are classified as having "primary" SS. Because of this heterogeneity, attempts have been made to identify subsets of patients that would permit more reliable prediction of the course of primary SS in the affected people. ${ }^{45}$

Adhesion molecules regulate cell-cell and cell-matrix interactions and determine lymphocyte homing to different lymphoid organs and sites of inflammation. ${ }^{6}$ Such molecules have been classified into several families, of which the selectins are one. ${ }^{7}$ L-selectin (CD62L) mediates leucocyte rolling on vascular endothelium at sites of inflammation and the recirculation of lymphocytes through the binding to high endothelial venules of peripheral lymph nodes. ${ }^{78}$ Indeed, leucocytes from mice lacking L-selectin (CD62L) have deficiencies in both functions. ${ }^{9}$ L-selectin (CD62L) is constitutively expressed on the surface of most leucocytes, including lymphocytes, neutrophils, monocytes, eosinophils, haematopoietic progenitor cells, and immature thymocytes. L-selectin (CD62L) is cleaved enzymatically from the leucocyte surface membrane after cell activation and released into the bloodstream. ${ }^{10}$ Soluble (s) L-selectin (CD62L) is functionally active and is present at high concentrations in human serum. ${ }^{11}$

Primary SS is associated with lymphocytic infiltration in salivary, lacrimal and other exocrine glands. The mechanism of lymphocytic infiltration is not known. The interaction between adhesion molecules, expressed on the surface of lymphocytes, and their specific ligands, expressed on endothelial cells and subsequently other cells in exocrine glands, may be the main mechanism for lymphocyte infiltration into sites of inflammation in this disease, contributing to the retention of lymphocytes in target organs of the autoimmune attack. No information is yet available on the physiological and clinical significance of the circulating shed forms of adhesion molecules in primary SS. This study was undertaken to determine sL-selectin (CD62L) concentrations in patients with primary SS and to evaluate the relation with the clinical and immunological features of SS.

\section{Methods}

PATIENTS

We included 40 consecutive patients (38 women and two men) with a mean age at onset of SS of 51 years (range 24-78). All patients fulfilled four or more of the preliminary diagnostic criteria for SS proposed by the European Community Study Group in $1993 .^{12}$ All patients underwent a complete history and 


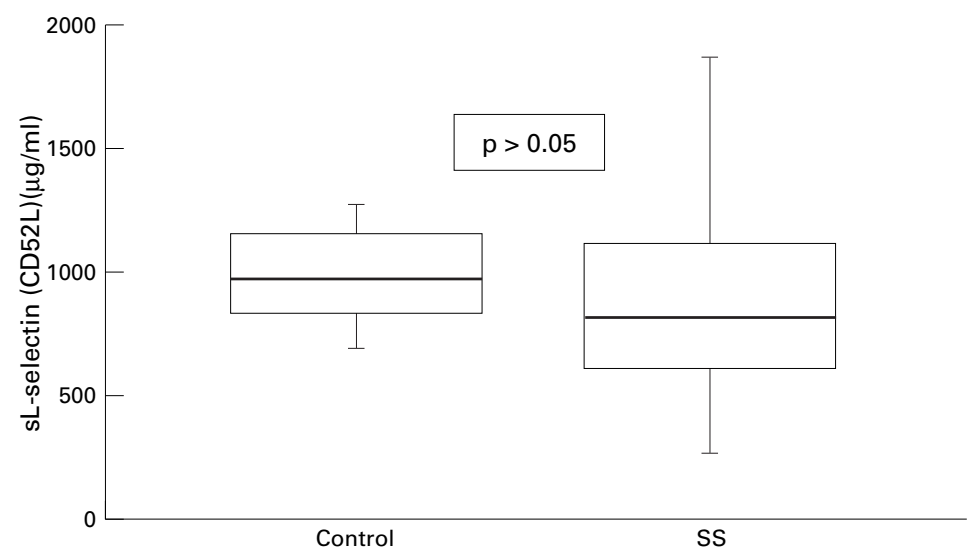

Figure 1 Serum concentrations of soluble L-selectin in patients with Sjögren's syndrome and controls. Box plots indicate the overall range (error bars), 25-75\% range (boxes) and median value (horizontal lines).

physical examination, and diagnostic tests for SS were applied according to the recommendations of the European Community Study Group. $^{12}$ Ten $(25 \%)$ patients had disease limited to the exocrine glands, and the remaining $30(75 \%)$ had one or more of the following extraglandular manifestations: arthralgia and/or arthritis, Raynaud's phenomenon, interstitial pneumonitis (evidence of interstitial fibrosis on chest radiography and/or in the high resolution computed tomography), cutaneous vasculitis (demonstrated by cutaneous purpura and skin biopsy), autoimmune thyroiditis (positive autoantibodies and/or altered thryroid function), peripheral neuropathy (demonstrated by the clinical picture and nerve conduction tests) and liver involvement (altered liver function tests and/or liver biopsy).

The serum concentrations of sL-selectin (CD62L) of these patients were compared with those of the 33 healthy blood donors from our hospital blood bank.

\section{LABORATORY STUDIES}

A sandwich enzyme linked immunosorbent assay (ELISA) to detect the soluble form of human L-selectin (CD62L) was performed as previously described, with slight modifications. ${ }^{11}$ Anti-L-selectin (CD62L) mAb LAM1-101 diluted to $3 \mu \mathrm{g} / \mathrm{ml}$ was used as the capture antibody. The presence of sL-selectin was shown with biotinylated antiLAM1-116 monoclonal antibody at $3 \mu \mathrm{g} / \mathrm{ml}$ and avidin-horseradish peroxidase, with O-phenylene-diamine $(0.125 \%$ wt/vol, Sigma, St Louis, MO) as substrate. Human serum samples were run in triplicate and diluted at $1 / 40$ to obtain a measurement in the linear range of our assay. Absorbances at $450 \mathrm{~nm}$ were measured using an MRX Microplate ELISA reader (Dynatech, Denkendorf, Germany). The concentration of sL-selectin was determined by using a standard curve constructed for each ELISA plate with recombinant L-selectin (CD62L) and results are expressed as $\mu \mathrm{g} / \mathrm{ml}$.

Immunological tests included determination of antinuclear antibodies (ANA) by indirect immunofluorescence using mouse liver as substrate, antibodies to double stranded DNA by
Table 1 Mean serum sL-selectin (CD62L) in SS patients grouped according to the presence or absence of extraglandular and immunological features

\begin{tabular}{llll}
\hline & \multicolumn{2}{l}{ sL-selectin (mean (SEM)) } & \\
\cline { 2 - 3 } & \multicolumn{1}{c}{ Present } & Absent & \\
\hline Extraglandular manifestation & & \\
Articular involvement & $766(89)$ & $958(96)$ & NS \\
Raynaud's phenomenon & $1275(112)$ & $789(69)$ & 0.007 \\
Cutaneous vasculitis & $936(198)$ & $843(68)$ & NS \\
Liver involvement & $839(162)$ & $868(73)$ & NS \\
Autoimmune thyroiditis & $1162(113)$ & $787(72)$ & 0.02 \\
Interstitial pneumonitis & $1286(247)$ & $839(67)$ & NS \\
Peripheral neuropathy & $863(204)$ & $861(67)$ & NS \\
Immunological manifestation & $817(76)$ & $936(124)$ & NS \\
ANA & $891(126)$ & $838(81)$ & NS \\
Anti-Ro/SS-A & $952(158)$ & $841(75)$ & NS \\
Anti-La/SS-B & $993(95)$ & $684(70)$ & 0.01 \\
RF & $1016(236)$ & $848(75)$ & NS \\
Cryoglobulins & NS & \\
Hypocomplementaemia & $1055(286)$ & $768(71)$ & NS \\
\hline
\end{tabular}

Farr's technique, precipitating antibodies to the extractable nuclear antigens Ro/SS-A and $\mathrm{La} / \mathrm{SS}-\mathrm{B}$ by counterimmunoelectrophoresis and rheumatoid factor (RF) by latex fixation and Waaler-Rose tests. Complement factors (C3 and C4) were estimated by nephelometry (Behring BNA nephelometer). Serum cryoglobulinaemia was measured after centrifugation. Centrifugated serum was incubated at $4^{\circ} \mathrm{C}$ for seven days and examined for cryoprecipitation.

\section{STATISTICAL ANALYSIS}

We used conventional $\chi^{2}$ and Fisher's exact test to analyse qualitative differences, Student's test for the comparison of means in large samples of similar variance, and the non-parametric Mann-Whitney U test for small samples. A value of $p<0.05$ was taken to indicate statistical significance. This statistical analysis was performed by means of the SPSS program using the information stored in the database program.

\section{Results}

We measured the serum concentrations of sL-selectin (CD62L) in 40 patients with primary SS and in 33 healthy blood donors. The mean (SEM) values of sL-selectin (CD62L) were 861 (66) $\mu \mathrm{g} / \mathrm{ml}$ for patients with SS and $986(180) \mu \mathrm{g} / \mathrm{ml}$ for healthy blood donors, but there was no significant difference (fig 1).

The most common extraglandular manifestations in our patients with primary SS were articular involvement in $20(50 \%)$ patients, liver involvement in nine (23\%), peripheral neuropathy in eight $(20 \%)$, cutaneous vasculitis in eight $(20 \%)$, autoimmune thyroiditis in eight $(20 \%)$, Raynaud's phenomenon in six $(15 \%)$ and interstitial pneumonitis in two (5\%). Serum sL-selectin (CD62L) concentrations were significantly higher in patients with Raynaud's phenomenon (1275 (112) $\mu \mathrm{g} / \mathrm{ml} v$ 789 (69) $\mu \mathrm{g} / \mathrm{ml}, \mathrm{p}=0.007$ ) and autoimmune thyroiditis $(1162(113) \mu \mathrm{g} / \mathrm{ml} v 787+69 \mu \mathrm{g} / \mathrm{ml}$, $\mathrm{p}=0.02$ ) when compared with patients without these manifestations (table 1).

The most frequent immunological features were: ANA in $25(63 \%)$ patients, $\mathrm{RF}$ in 23 (58\%), anti-Ro/SS-A antibodies in 13 (33\%), 
cryoglobulinaemia in 6 of $34(18 \%)$, hypocomplementaemia in 5 of $30(17 \%)$ and anti-La/ SS-B antibodies in five $(13 \%)$ patients. No patient had a positive titre of anti-dsDNA or anti-Sm antibodies. Serum sL-selectin (CD62L) concentrations were significantly higher in patients with RF compared with those without $\mathrm{RF}$ (993 (95) $\mu \mathrm{g} / \mathrm{ml}$ compared with $684(70) \mu \mathrm{g} / \mathrm{ml}, \mathrm{p}=0.01$ ) (table 1 ).

\section{Discussion}

Investigation into adhesion molecule pathophysiology in primary SS is scarce and has focused on characterising adhesion molecule expression in salivary gland biopsy specimens. ${ }^{13} \mathrm{~L}$-selectin was found to be expressed by $18 \%$ of the infiltrating cells in labial salivary glands from patients with primary SS, ${ }^{13}$ which is considerably less than in the peripheral blood, and the comparatively reduced number of CD62 L positive lymphocytes might be attributable to shedding of the L-selectin (CD62L) after cell activation.

In our study, we found increased concentrations of circulating sL-selectin (CD62L) in patients with primary SS that present with some extraglandular manifestations. Firstly, patients with primary SS and Raynaud's phenomenon showed higher circulating concentrations of sL-selectin (CD62L). In primary SS, Raynaud's phenomenon is not constantly observed, and it could result from a specific immunological aggression. The molecule analysed in our study promotes the attachment of diverse leucocytes to endothelium, and thereby together regulates the local traffic of neutrophils, monocytes, and lymphocytes. L-selectin is shed after cell activation, and raised sL-selectin (CD62L) concentrations may reflect a higher grade of activation of the leucocytes occurring in this subset of patients with primary SS and associated Raynaud's phenomenon.

A second subset of patients with primary SS, those with autoimmune thyroiditis, showed higher values of circulating sL-selectin (CD62L) in their sera. Autoimmune thyroiditis is an organ specific, autoimmune destruction of the thyroid gland mediated by $\mathrm{T}$ lymphocytes, with anti-thyroglobulin and antimicrosomal antibody formation, frequently associated to SS. ${ }^{14}$ Stimulation of thyroid epithelial cells in vitro with tumour necrosis factor $\alpha$ or interferon $\gamma$ induced expression of ICAM-1. ${ }^{15}$ ICAM-1 and LFA-3 expression has been identified on thyroid cells in autoimmune thyroiditis, and it has been suggested that these molecules have functional importance in leading to the adherence of $\mathrm{T}$ cells to this target organ. ${ }^{16}$ Adhesion molecules might participate in the pathophysiology of autoimmune thyroiditis in primary SS patients.

The presence of Raynaud's phenomenon, autoimmune thyroiditis and rheumatoid factor is associated with higher concentrations of circulating sL-selectin (CD62L) in the sera of patients with primary SS. Measurement of sL-selectin (CD62L) in primary SS may also provide guidance in the selection of clinical subsets of patients in which pharmacological blockade of adhesion molecules should be attempted, to interfere with leucocyte migration and function.

Funding: supported by grants FIS 97/0669 and FIS 99/0280 from the Fondo de Investigaciones Sanitarias. M Ramos-Casals is a Research Fellow sponsored by a grant from the Hospital Clínic.

1 Moutsopoulos HM, Chused TM, Mann DL, Klippel JH, Fauci AS, Frank MM, et al. Sjögren's syndrome (sicca syndrome): Current issues. Ann Intern Med 1980;92:212-26.

2 Talal N. Clinical and pathogenetic aspects of Sjögren's syndrome. Semin Clin Immunol 1993;6:11-20.

3 Anaya JM, Gutierrez M, Espinosa LR. Síndrome de Sjögren primario. Manifestaciones clínicas extraglandulares. Rev Esp Reumatol 1994;21:337-42.

4 Ramos M, Cervera R, García-Carrasco M, Miret C, Muñoz FJ, Espinosa G, et al. Síndrome de Sjögren primario: características clínicas e inmunológicas en una serie de 80 pacientes. Med Clin (Barc) 1997;108:652-7.

5 Ramos-Casals M, Cervera R, Font J, García-Carrasco M, Espinosa G, Reino S, et al. Young onset of primary Sjögren's syndrome: clinical and immunological characteristics. Lupus 1998;7:202-6.

6 Springer TA. Adhesion receptors of the immune system. Nature 1990;346:425-34.

7 Springer TA. Traffic signals for lymphocyte recirculation and leukocyte emigration: the multistep paradigm. Cell 1994;76:301-14.

8 Tedder TF, Steeber DA, Chen A, Engel P. The selectins vascular adhesion molecules. FASEB J 1995;9:866-73.

9 Tedder TF, Steeber DA, Pizcueta P. L-selectin-deficient mice have impaired leukocyte recruitment into inflammatory sites. J Exp Med 1995;181:2259-64.

10 Chen A, Engel P, Tedder TF. Structural requirements regulate endoproteolytic release of the L-selectin (CD62L) adhesion receptor from the cell surface of leukocytes. J Exp Med 1995;182:519-30.

11 Spertini O, Schleiffenbaum B, White-Owen C, Ruiz Jr P, Tedder TF. ELISA for quantitation of L-selectin shed from leukocytes in vivo. J Immunol Methods 1992;156:115-23.

12 Vitali C, Bombardieri S, Moutsopoulos HM, Balestrieri G, Bencivelli W, Bernstein RM, et al. Preliminary criteria for the classification of Sjogren's syndrome. Arthritis Rheum 1993;36:340-7

13 Aziz KE, McCluskey PJ, Wakefield D. Expression of selectins (CD62 E,L,P) and cellular adhesion molecules in primary Sjögren's syndrome: questions to immunoregulation. Clin Immunol Immunopathol 1996;80:55-66.

14 Cervera R, Ramos M, García-Carrasco M, Font J, Gaya J, Ingelmo $M$. Prevalence of thyroid disease in a series of 92 patients with primary Sjögren's syndrome. Br J Rheumatol 1997;36 (suppl 1):46.

15 Weetman AP, Cohen S, Makgoba MW, Borysiewicz LK. Expression of an intercellular adhesion molecule, ICAM-1, by human thyroid cells. J Endocrinol 1989;22:185-91.

16 Tandon N, Makgoba MW, Gahmberg CG, Weetman AP. The expression and role in T cell adhesion of LFA-3 and ICAM-2 on human thyroid cells. Clin Immunol Immunopathol 1992;64:30-5. 